\title{
Analysis of Students Open Feedback After Their Participation in a Multinational Design Project
}

\author{
Jorge Rodriguez, $\mathrm{PhD}^{1}$, Miguel Nunez Del Prado Cortez, $\mathrm{PhD}^{2}$, Ivan E. Esparragoza, $\mathrm{PhD}^{3}$, \\ and Hugo Alatrista Salas, $\mathrm{PhD}^{2}$ \\ ${ }^{1}$ Western Michigan University, USA, jorge.rodriguez@wmich.edu \\ 22Universidad del Pacífico, Perú, m.nunezdelpradoc@up.edu.pe, h.alatristas@up.edu.pe \\ ${ }^{3}$ The Pennsylvania State University - Brandywine, USA, iee1@psu.edu
}

\begin{abstract}
Participation by students in multinational engineering design projects is an activity that has been implemented at academic institutions with the objective of exposing the students to globalization. Such collaborations are becoming a very important practice that prepare students to be aware of the various aspects that are faced whenever work is performed in a global environment. There have been several approaches for the implementation of these activities in the curriculum, and the one presented here is an engineering design project conducted with the participation of students from six different countries. As an assessment of the students' experience, three specific open-ended questions were asked at the end of their participation. These questions cover the basic information of like-dislike-recommendation regarding the collaborative experience. Proper interpretation of responses to openended questions is a complex task, and several approaches have been reported. Data analytics technique of topic modelling is utilized in order to get an objective assessment. Based on the valid responses post-event $(n=95)$ from the participants to the three basic questions, together with the corresponding demographic information, the feedback is evaluated and conclusions are drawn regarding the effect of ethnicity, which is directly related to geographic location. Positive feedback related to the value of the international experience, negative feedback related to logistics, and recommendations related to communication have been identified based on ethnicity grouping. These conclusions validate previous ones drawn based on numerical feedback on motivation, and will be utilized to improve the offering of a similar multinational collaboration engineering design project to students.
\end{abstract}

Keywords: Student feedback, open-ended survey, multinational project, international collaboration.

\section{INTRODUCTION}

Global engineering collaborations have become a fundamental component in current product design activities. In fact, because of the growing complexity of today's products, their development requires to integrate knowledge and skills across disciplines and organizations resulting in a high levels of collaboration between diverse parties. Working on a collaborative environment provides the advantages of having complementary resources, information and ideas that compensate for the limitations of a design done individually. The expected result is a product that could not have been achieved by any individual acting alone.

A main catalyst that has increased collaboration in engineering design projects is the growth in Information Technologies (IT), in particular communication and computational capabilities. These developments improves the capabilities for sharing information across teams of designers located around the world, and provides the infrastructure necessary for an integrated and distributed engineering environment [1]. However, working on multi- or interdisciplinary projects is inherently challenging, and effective collaboration may require new ways to share information. These challenges "include aspects such as differences in language, culture, education, and government regulations, as well as teams working across different time zones around the world" [2]. As result of these challenges, there is a growing demand for professionals who are able to effectively and efficiently communicate and collaborate with partners from different countries and cultures [3].

It is evident that there is an educational challenge regarding training experiences offered to students so that they acquire the skills necessary to operate in an interdisciplinary and intercultural collaborative environment. As a result, many engineering programs are incorporating educational experiences to better prepare students for the global working environment. Multinational collaborative projects are a good example of such experiences used to promote the development of global competencies in students, combined with the additional technical knowledge of a particular discipline. These projects are characterized by having teams geographically dispersed but working on a common design project. A multinational collaborative project involving students from the US, Latin America and Europe [4] is the one considered in this study. A main reason to implement this project comes from the notion that while international projects offer new opportunities for diversification and expansion, they also introduce risks because of cultural, administrative, geographic, marketing, and economic differences between the organizations involved [5]. Therefore, students must be prepared also to understand and deal with these challenges.

\section{BACKGROUND}

Assessment of those collaborative experiences is essential in order to define proper interventions that improve the overall benefits for the students. Direct feedback from participants is the most acceptable vehicle to collect evaluation data. At the same time, in order to avoid any bias in such evaluations, openended questions are the better option to get feedback from participants. For this report, data was collected via an online survey that collected information on three main areas: 
demographics, motivation of students, and direct feedback. Analyses of the motivational aspects of the survey have been reported previously $[6,7]$. The objective in this report is to extract important trends in the feedback provided by the engineering students participating in a multinational collaborative project, indicating any specific dominant demographic factor.

International collaboration in engineering academic institutions is something that has been requested by professional engineering societies and practitioners in industry, to the level that several institutions located in Latin America have already begun to answer the call to create an internationally prepared engineer $[8,9]$, with several efforts focusing on the issues and approaches for preparing engineering educators [10]. At the same time various, as previously reported [11], organizations have indicated the need to "promote the formation of world-class engineers for the Americas as well as an assortment of resources and opportunities that facilitate the participation of faculty, staff, and students from Latin America and the Caribbean in a variety of engineering education experiences."

A collaborative network of institutions from the Americas and Italy has developed and implemented collaborative multinational design projects as part of academic experiences for their students. The main goal of these projects is to foster international collaboration and to offer an opportunity to the students to develop professional skills through international teamwork effort in the solution of a design problem. However, a real challenge of this practice has been to create an effective interaction among the students participating in this type of projects and to maintain the flow of information, and students' engagement in the project and in their learning [12]. The multinational collaborative project used in this study follows the parallel projects approach in which teams from different countries work on the same design project, and clusters of collaboration are formed for the international teams to exchange information and enrich the final conceptual design. Clusters are created in such a way that teams formed on each participating institution are paired with teams from other countries to enforce exchange of information and collaborative work. The interaction of the students is expected to take place using the formal means of communication that have been established for the collaboration and they are: audio-video conferences (Adobe Connect), email, and a cloud storage application selected for the project. Additionally, teams are allowed to use informal means of communication to keep the interaction active during the project and this includes social media, texting, cellular phones and other online communication tools as the teams consider appropriate. The projects last for eight weeks and teams are required to interact for at least five weeks including four scheduled video-conferences.

\section{PROPOSED APPROACH}

To identify trends in the responses by student participants to feedback open-ended questions is the objective of this study.
Those trends will be based on the use of a data analytics approach to investigate any possible relationship between text answers and some of the demographic factors collected in the surveys. The specific analytical approach is topic modelling, and its application is by means of utilizing an implementation in R-language, with the corresponding links to the data analytic routines.

Topic modeling is a non-supervised technique to cluster documents in different groups about a specific theme or topic. The idea behind this technique is to group related words like student, homework, teacher in a chosen topic, like university. There are different techniques such as Latent Dirichlet Allocation (LDA) [13], Term Frequency, Inverse Document Frequency [14], and Non-negative Matrix Factorization. More specifically, the Latent Dirichlet Allocation algorithm for Topic Modeling assumes that documents are generated from a mixture of topics. Thus, given a set of documents, the LDA algorithm iteratively infer the topics that can be extracted for a specific theme. LDA uses a document-term matrix representation of all documents and words in a corpus. Then, taking into account the $k$ number of topics, this matrix is decomposed into two matrices, a document-topics one and a term matrix. The former represents the probability of a document belonging to a given topic $k$. The latter models the probability of words to be in that given topic $k$. Subsequently, the weights in the matrices are updated taking into account the proportion of words in documents that are assigned to the topic $k$ and the proportion of topics overall documents that come from word $w$. These steps are repeated until convergence is accomplished in the process, resulting in the identifications of topics or themes represented by the documents (i.e., survey responses) provided. In this cases the user has the option to specify the number of topics $k$ to be identified, which is usually based on establishing a balance between quantity of topics and their importance.

Similarly, another data analytics technique applied in this case is Sentiment Analysis, or opinion mining, which is an approach that attempts to determine whether an opinion, expressed in written text, is positive, negative or neutral, with respect to specific entities/factors or characteristics [15]. These entities may be products, services, organizations, individuals, events or topics [16]. Nowadays, the Sentiment Analysis tasks are typically performed by corporations or businesses looking for relevant information for their stakeholders. Companies collect and analyze massive amounts of textual data, generated in, for example, social networks and surveys (administered by themselves or by a third-party agency) with the intention to identify specific trends or conclusions that support the mission or objective of the corporation/business.

In academic institutions, an approach such as Sentiment Analysis can be used to evaluate the perception or the motivation of students concerning development or implementation of specific task(s) in a course, or even for a new course or field of study. In fact, at the end of a semester, some lecturers perform a survey to capture feedback related to the

$1^{\text {th }}$ LACCEI International Multi-Conference for Engineering, Education, and Technology: "Innovation in Education and Inclusion", 19-21 July 2018, Lima, Peru. 
appropriateness of the task or topic/course implemented. Sentiment Analysis can be performed in two ways:

- using supervised machine learning methods

- using dictionaries

The first method uses a well-known machine learning technique called classification. The classification needs a labeled corpus, i.e., a set of positives and negatives documents and, a classification algorithm "learn" from using this labeled corpus to predict the class (positive/negative) when a new document without class arrives. Several articles have been published involving the application of this method [17-19].

The idea behind the second method is to use two, or more, dictionaries. One of positive word(s) and the other one containing negative word(s). This approach starts parsing each word in each document and comparing it with words in both dictionaries. If a word in a document matches with a word in a positive dictionary, the positive sentiment index of the document counts as plus one. The strategy is the same for negative words in the document. Finally, for each document, the number of positive and negative words in the document are compared, and the sentiment (positive or negative) is obtained. This method has been presented and applied in several reports in the literature [20-22], and in the present study these approach is utilized to deduce the polarity embedded in the responses to open-ended questions in the administered survey.

\section{RESULTS}

This study is based on data collected during the multinational collaboration that took place during the Fall 2015 semester. In this instance, 54 international teams from seven different institutions representing six countries were grouped in 12 clusters. Six clusters had five international teams and six clusters had four international teams, as can be seen in Table I. The project consisted on the design of an appropriate workspace for prototyping with hand-tools. The following requirements were defined for the project: the workplace was to accommodate up to four people working simultaneously; workers with various types of disabilities should be able to use the facility; workbenches were to be utilized for prototyping and tools/materials storage; workbenches were to be installed in $34 \mathrm{~m}^{2}$ room with the footprint of the workbenches limited to a maximum of $50 \%$ of the room space.

The survey administered after students participation had five demographics questions and three open-ended questions. The first five questions allowed characterization of the population participating in the study. The last three question provided the feedback for assessment and intervention purposes. The total number of participants in the collaborative effort was 218 , with 95 responses captured online at the end of the semester, but only 87 of them considered as valid responses, i.e., $40 \%$ response rate. The main demographic data collected was (one question is related to their enrollment in the collaborative effort):

1. What is your location? [Answers vary between 1 and 6 , based on country].
2. What is your class standing? [Answers vary between 1 and 5, based on year in college - 1 is first year].

3. What is your gender? [Answers vary between 1 and 3, male/female/other].

4. What is your ethnicity? [Answers vary between 1 and 6 , based on race].

The three questions included in the questionnaire to capture the appreciation of the students are open-ended and the answers by the students were given in text format (online). The questions are the following ones:

- (Q1) What did you like most about the collaborative project?

- (Q2) What did you like least about the collaborative project?

- (Q3) What would you recommend to improve the collaborative experience?

TABLE I

Clusters TEAM DisTRIBUTION

\begin{tabular}{|c|c|c|c|c|c|c|c|c|}
\hline Cluster & BR & CH & EC & HO & IT & US1 & US2 & Total \\
\hline 1 & & 2 & 1 & & & 1 & 1 & 5 \\
\hline 2 & & 2 & 1 & & & 1 & 1 & 5 \\
\hline 3 & & 2 & 1 & & & 1 & 1 & 5 \\
\hline 4 & & 2 & 1 & & & 1 & & 4 \\
\hline 5 & & 2 & 1 & & & 1 & & 4 \\
\hline 6 & & 2 & 1 & & & 1 & & 4 \\
\hline 7 & & 2 & & 1 & 1 & 1 & & 5 \\
\hline 8 & & 2 & & 1 & & 1 & 1 & 5 \\
\hline 9 & & 2 & & 1 & & 1 & 1 & 5 \\
\hline 10 & & 2 & & 1 & & 1 & & 4 \\
\hline 11 & & 2 & & 1 & & 1 & & 4 \\
\hline 12 & 1 & 2 & & & & 1 & & 4 \\
\hline Total & $\mathbf{1}$ & $\mathbf{2 4}$ & $\mathbf{6}$ & $\mathbf{5}$ & $\mathbf{1}$ & $\mathbf{1 2}$ & $\mathbf{5}$ & $\mathbf{5 4}$ \\
\hline
\end{tabular}

BR: Brazil/CH: Chile/EC: Ecuador/HO: Honduras/IT: Italy/US1: United

States (University 1)/US2: United States (University 2)

The datasets from these questions were used in the analyses presented in this study, basically the application of the Topic Modeling and the Sentiment Analysis approaches to the textual data of the surveys. The first step is to take a look at the actual data collected based on demographics.

First, we explore the dataset to analyze the number of answered surveys corresponding to each of the demographic factors, such as standing, gender, and ethnicity. Figure 1 illustrates information regarding standing, where the largest group represents first-year students; Figure 2 illustrates the breakdown based on gender, the participants were $83 \%$ male and $17 \%$ female; and Figure 3 illustrates the ethnicity of the participants, indicating that the largest group is $\# 5$, which represents Caucasian ethnicity. Based on these results, and as well taking into account recommendations for the Topic Modeling using LDA algorithm, it is decided to perform a grouping based on ethnicity, which implies that the results will be a reflection of US student population and non-US population. There is high level of correlation between ethnicity \#5 and a participant being from a US academic institution.

$16^{\text {th }}$ LACCEI International Multi-Conference for Engineering, Education, and Technology: "Innovation in Education and Inclusion”, 19-21 July 2018, Lima, Peru. 


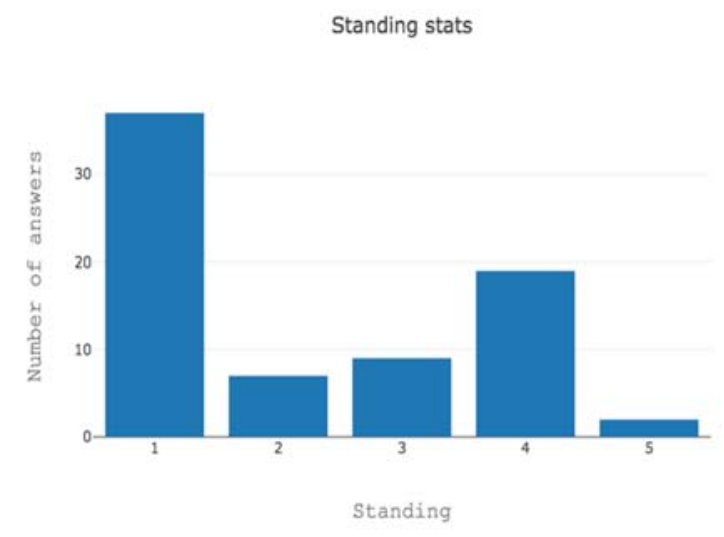

Figure 1. Breakdown of respondents based on Class Standing.

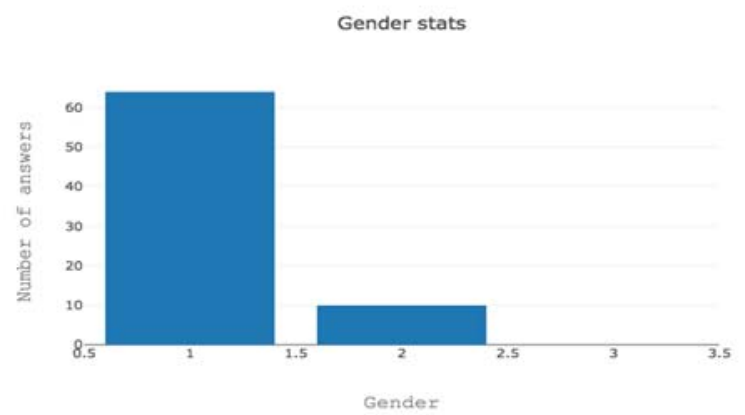

Figure 2. Breakdown of respondents based on Gender.

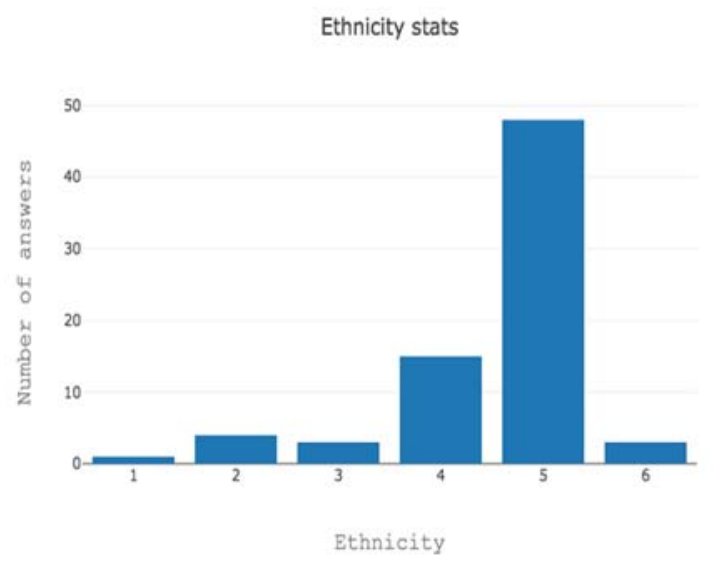

Figure 3. Breakdown of respondents based on Ethnicity.

Performing Topic Modeling to total dataset, and selecting the identification of three topics (Table II), results in positive responses regarding the international experience (country), the global teamwork (team), and the concept (idea); with negative responses related to communication, time, and work level; and suggestions related to timing and communication.
TABLE II

TOPIC MODELING BASED ON ALL ANSWERS IN THE SURVEY

\begin{tabular}{|l|l|l|l|}
\hline & \multicolumn{1}{|c|}{ Topic1 } & \multicolumn{1}{c|}{ Topic2 } & Topic3 \\
\hline $\mathbf{Q 1}$ & $\begin{array}{l}\text { country } \\
\text { people } \\
\text { different }\end{array}$ & $\begin{array}{l}\text { student } \\
\text { meeting } \\
\text { team }\end{array}$ & $\begin{array}{l}\text { working } \\
\text { idea } \\
\text { liked }\end{array}$ \\
\hline $\mathbf{Q 2}$ & $\begin{array}{l}\text { team } \\
\text { communication } \\
\text { would }\end{array}$ & $\begin{array}{l}\text { group } \\
\text { work }\end{array}$ & $\begin{array}{l}\text { team } \\
\text { working } \\
\text { hard }\end{array}$ \\
\hline $\mathbf{Q 3}$ & $\begin{array}{l}\text { time } \\
\text { work } \\
\text { group }\end{array}$ & $\begin{array}{l}\text { team } \\
\text { working } \\
\text { communication }\end{array}$ & $\begin{array}{l}\text { group } \\
\text { team } \\
\text { time }\end{array}$ \\
\hline
\end{tabular}

Once the analysis focuses on the $\# 5$ group (Table III), again the positive indicates the international experience and global teamwork, and diversity of ideas; with negative responses related to language (not communication in general), and timing; and suggestions related to teamwork, language and timing.

TABLE III

TOPIC MODELING BASED ON ANSWERS IN THE SURVEY FOR

\begin{tabular}{|c|l|l|l|}
\hline E5 & Topic1 & \multicolumn{1}{|c|}{ Topic2 } & Topic3 \\
\hline Q1 & $\begin{array}{l}\text { idea } \\
\text { different } \\
\text { country }\end{array}$ & $\begin{array}{l}\text { team } \\
\text { working } \\
\text { international }\end{array}$ & $\begin{array}{l}\text { different } \\
\text { working } \\
\text { project }\end{array}$ \\
\hline Q2 & $\begin{array}{l}\text { project } \\
\text { working } \\
\text { different }\end{array}$ & $\begin{array}{l}\text { team } \\
\text { language } \\
\text { time }\end{array}$ & $\begin{array}{l}\text { group } \\
\text { time } \\
\text { meeting }\end{array}$ \\
\hline Q3 & $\begin{array}{l}\text { team } \\
\text { project } \\
\text { group }\end{array}$ & $\begin{array}{l}\text { time } \\
\text { meeting } \\
\text { language }\end{array}$ & $\begin{array}{l}\text { time } \\
\text { hard } \\
\text { group }\end{array}$ \\
\hline
\end{tabular}

For the other group, i.e., non-\#5 group (Table IV), the positive responses related more to the international experience and people involved, with negative responses on specific communication and timing, and suggestions on collaboration, communication and timing.

Table V shows the results of the Sentiment Analysis, whose value ranges from negative to positive, and zero being neutral. These results, overall and split groups, indicate a positive sentiment but with most values close to the neutral point (10 points scale). The only negative is in Q2 for the non\#5 group, where communication (language) was previously identified. 
TABLE IV

TOPIC MODELING BASED ON ANSWERS IN THE SURVEY FOR ETHNICITY DIFFERENT FROM (\#5)

\begin{tabular}{|l|l|l|l|}
\hline E/5 & Topic1 & Topic2 & Topic3 \\
\hline Q1 & $\begin{array}{l}\text { people } \\
\text { sharing } \\
\text { country }\end{array}$ & $\begin{array}{l}\text { liked } \\
\text { student } \\
\text { de }\end{array}$ & $\begin{array}{l}\text { meet } \\
\text { like } \\
\text { different }\end{array}$ \\
\hline Q2 & $\begin{array}{l}\text { contact } \\
\text { voice } \\
\text { call }\end{array}$ & $\begin{array}{l}\text { team } \\
\text { work } \\
\text { country }\end{array}$ & $\begin{array}{l}\text { team } \\
\text { meet } \\
\text { time }\end{array}$ \\
\hline Q3 & $\begin{array}{l}\text { project } \\
\text { group } \\
\text { voice }\end{array}$ & $\begin{array}{l}\text { team } \\
\text { work } \\
\text { country }\end{array}$ & $\begin{array}{l}\text { team } \\
\text { meet } \\
\text { every }\end{array}$ \\
\hline
\end{tabular}

TABLE IV

SENTIMENT ANALYSIS BASED ON ALL ANSWERS IN THE SURVEY

\begin{tabular}{|c|c|c|c|}
\hline & $\mathbf{E} / \mathbf{5}$ & $\mathbf{E 5}$ & All \\
\hline Q1 & 1.269230 & 0.75 & 0.932432 \\
\hline Q2 & -0.115384 & 0.1875 & 0.081081 \\
\hline Q3 & 1.130434 & 1.111111 & 1.117647 \\
\hline
\end{tabular}

\section{CONCLUSIONS}

In this work, analysis of end-of-participation feedback is analyzed. The feedback is provided by students participating in a multinational engineering design project, and it is in text format as answers to open-ended questions regarding basic likedislike-recommendation sequence. The use of a Topic Modeling algorithm results in the identification of themes (topics) that can be extracted from the text provided for each one of the three open-ended questions. The text answers were grouped based on ethnicity, which is highly correlated to location, due to the relative percentages represented in the collected responses. Topic Modeling with an LDA approach provides useful information, presenting that:

- for positive aspects (i.e., international experience, global collaboration, and concept) the two groups have similarities, and are reflected in the overall topics extracted

- for negative aspects, the communication and timing themes are common, with specific indication that language is an issue for non-US participants

- for recommendations, there are similarities in both groups, and basically are directed at addressing the negative aspects (i.e., communication and timing).

The Sentiment Analysis indicates an overall positive feeling, but with an index close to neutrality.
These results indicate that even when all students appreciate the international collaboration experience, there were some issues that need to be addressed. In terms of communication, which is an expected challenge, the intervention that is suggested is to make participants more aware of this (and other) issues when the project is introduced perhaps expecting additional understanding from the students. On the issue of timing, the intervention that is suggested is to have better logistics, offering more flexibility to the students to have less constrains in terms of meeting sessions. Future offerings of this experience will implement the interventions suggested here, with the goal of having a more positive global collaboration.

\section{ACKNOWLEDGEMENTS}

The authors would like to acknowledge the participation of faculty members that worked in the collaboration project by including the project into their courses, thus having the participation of students in the project and having pre- and postfeedback. Specifically, Carlos Saccheli, from Universidade Federal de Santa Catarina, Brazil; Sheila Lascano, from Universidad Tecnica Federico Santa Maria, Chile; Jorge Duque, from Escuela Superior Politecnica del Litoral, Ecuador; Jared Ocampo from Universidad Tecnologica Centroamericana, Honduras; Roberto Vigano, from Politecnico di Milano, Italy; and Uladeslau Ivashyn, from The Pennsylavania State University - Brandywine, USA.

\section{REFERENCES}

[1] Pfleeger, S. L., \& Atlee, J. M. (1998). Software Engineering: Theory and Practice. Pearson Education India.

[2] Törlind, P. (2016). Collaborative Design. Journal of the Indian Institute of Science, 95(4), 353-364

[3] DeVoss, D., Jasken, J., \& Hayden, D. (2002). Teaching intracultural and intercultural communication. A critique and suggested method. Journal of Business and Technical Communication, 16, 69-94.

[4] Esparragoza, I. E., Nunez, J., Lascano, S., Ocampo, J. R., Vigano, R., \& Duque, J. (2015). Assessment of interaction in multinational projects: A comparison based on geographical location. International Conference on Interactive Collaborative Learning (ICL), pp. 347-354.

[5] Berteaux, F., Javernick-Will, A., (2015). Adaptation and Integration for Multinational Project-Based Organizations, Journal of Management in Engineering, vol. 31, no. 6, Nov. 2015.

[6] Esparragoza, I., Ocampo, J., Rodriguez, J., Vigano, R., Sacchelli, C., Duque, J., Lascano, S., and Ivashyn, U., (2017). Study of Interest and Perception of Value in Multinational Collaborative Design Projects among Engineering Students, Advances in Intelligent Systems and Computing, Springer International, pp.6-19.

[7] Rodriguez, J. and Esparragoza, I., (2017). Motivation of Engineering Students Participating in Multinational Design Projects - Comparison Based on Gender and Class Status, International Journal of Engineering Pedagogy, (Accepted, in press).

[8] Esparragoza, I., Ocampo, J., Rodriguez, J., Lascano, S., Ivashyn, U., Sacchelli, C., Vigano, R, and Duque, J., (2016). Engineering Students Motivation on Multinational Projects: A Comparison Based on Interest, Value, and Gender, Proceedings of the Fourteenth Latin American and Caribbean Conference for Engineering and Technology, Paper RP-268, July 2016.

[9] Lucena, J., Downey, G., Jesiek, B. and Elbers, S. (2008). Competencies Beyond Countries: The Re-Organization of Engineering Education in the

$16^{\text {th }}$ LACCEI International Multi-Conference for Engineering, Education, and Technology: "Innovation in Education and Inclusion”, 19-21 July 2018, Lima, Peru. 
US, Europe and Latin America. Journal of Engineering Education, (October), 433-447.

[10] Downey, G. L. and Beddoes, K. (2010) What is Global Engineering Education For? The Making of International Educators, Part I \& II - III. Synthesis Lectures on Global Engineering, Morgan \& Claypool Publishers.

[11] Esparragoza, I., Ocampo, J., Rodriguez, J., and Vigano, R, (2016). Study of Motivation of Engineering Students on Multinational Design Projects, IEEE Journal of Latin-American Learning Technologies (IEEE-RITA), (Accepted, in press).

[12] Esparragoza, I., Larrondo Petrie, M. M., Jordan, R., \& Paez Saavedra, J. (2007). Forming the Global Engineer for the Americas: Global Educational Experiences and Opportunities Involving Latin America and the Caribbean. AC 2007-576, p. 20.

[13] Blei, D. M., Ng, A. Y., \& Jordan, M. I. (2003). Latent dirichlet allocation. Journal of machine Learning research, 3(Jan), 993-1022.

[14] Blei, D. M. and Lafferty, J. D. (2009). Topic models. Text mining: classification, clustering, and applications, 10(71), 34 .

[15] Pang, B. and Lee, L. (2008). Opinion Mining and Sentiment Analysis. Foundations and Trends in Information Retrieval, 2, 1

[16] Liu, B. (2015). Sentiment Analysis: Mining Opinions, Sentiments and Emotions. Cambridge University Press, 90.

[17] Xia, R., Zong, C. and Li. S. (2011). Ensemble of feature sets and classification algorithms for sentiment classification, Information Sciences, 181, 1138

[18] Pang, B., Lee, L. and Vaithyanathan, S. (2002). Thumbs up? Sentiment Classification using Machine Learning Techniques. Proceedings of the Conference on Empirical methods in natural language processing, Jul. 0607, 2002, Philadelphia, USA, 79-86

[19] Singh, P. and Husain, M. (2014). Methodological study of opinion mining and sentiment analysis techniques. International Journal on Soft Computing, 5,11

[20] Taboada, M., Brooke, J., Tofiloski, M., Voll, K., and Stede, M. (2011). Lexicon-Based Methods for Sentiment Analysis, Computational Linguistics, 37, 267

[21] Lima, A. C., Nunes-de-Castro, L., and Corchado, J. M. (2015). A polarity analysis framework for Twitter messages. Journal of Applied Mathematics and Computation of Elsevier, 270, 756

[22] Wilson, T., Wiebe, J., and Hoffmann, P. (2005). Recognizing Contextual Polarity in Phrase-Level Sentiment Analysis, Proceedings of the Conference on Human Language Technology and Empirical Methods in Natural Language Processing, Oct. 06-08, 2005, Vancouver, Canada (Association for Computational Linguistics, USA), 347-354.

$1^{\text {th }}$ LACCEI International Multi-Conference for Engineering, Education, and Technology: "Innovation in Education and Inclusion”, 19-21 July 2018, Lima, Peru. 